\title{
Apoptosis Induced by Polyethylenimine/DNA Complex in Polymer Mediated Gene Delivery
}

\author{
Minhyung Lee \\ Department of Bioengineering, College of Engineering, Hanvang Cniversitw, Seoul 133-791, Korea \\ E-mail: minhymgahanyang.ackr \\ Recened November 3, 2006
}

\begin{abstract}
Polyethylenimine (PEI) has been widely investigated for delivery of DNA into cells. It was previously reported that there were at least two types of cytotoxicity in PEI-mediated gene delivery, immediate and delayed toxicities. PEI-mediated gene delivery protocols use net cationic complexes with an excess of PEI to maintain equilibrium between the complexed and dissociated forms in solution. In this study. toxicity of free PEI or PEV DNA complex was investigated. Human embry onic kidney 293 cells were incubated with free PEI or PEIDNA complex for 4 lurs. Then, the cells were analyzed at 6,24,48, and 96 hrs after the incubation. In MTT assay: the viability of the cells incubated with PEIDNA complex was continuously decreased with time, while that of the cells incubated with free PEI was not. On the contrany. the expression level of the luciferase gene increased gradually along with time. Release of DNAs from the complexes for transcription produces free PEIs in the cells. This process may proceed slowly due to high charge density of PEI and may be related to delayed toxicity: In addition, apoptotic cells were observed only in the cells incubated with the PELDNA complex from $2+$ hrs after the incubation. The results suggest that PELDNA complex contributes to the delayed toxicity by inducing apoptosis and that the delayed toxicity may be related to decomplexation of the complexes in the cells.
\end{abstract}

Key Words : Apoptosis, Gene delivery. Polyethỵlenimine, Toxicity

\section{Introduction}

Gene therapy is an intracellular delivery of genetic materials to produce therapeutic effects by producing proteins or blocking the expression of harmuful proteins. Since the first clinical trial. gene therapy has been rapidly developed to treat hard-to-cure diseases. ' For successfil gene therapy. there are two important considerations: therapeutic gene and delivery vector. Various delivery vectors have been developed and viral vectors are currently the most efficient carriers. ${ }^{2.3}$ However. intrinsic problems of viral vectors such as immunogenecity and oncogenic effects limit their applications to human gene therapy. ${ }^{4}$ Therefore, non-viral carriers have been developed as alternatives for viral carriers. Nonviral vectors have several advantages such as low immunogenecity. no size limit and low cost. ${ }^{3}$ In addition. it can be administered repeatedly. Non-viral vectors are composed of cationic polymers. cationic liposomes and their conjugates. Especially. polymeric vectors can be modified with appropriate ligands for specific cell targeting. ${ }^{56}$ Poly-L-lysine (PLL) and polyethylenimine (PEI) have been commonly used as polymeric vectors. ${ }^{7}$ PEI has higher transfection efficiency than PLL due to proton sponge effect. ${ }^{8 . \overline{7}} \mathrm{PEI}$ and its derivatives have been investigated for various gene delivery applications. However. PEI has relatively high cy totoxicity to cells. ${ }^{10}$ Therefore. many researches have been conducted to reduce the cytotoxicity of PEI by conjugation of polyethy lene glycol (PEG) or introduction of degradable bonds to the PEI backbone. ${ }^{50-14}$ It was previously suggested that PEI or PEL/DNA complex aggregates on the surface of plasma membrane and destabilizes it. which results in the rupture of the membrane..$^{15}$ In another report. it was suggested that PEI-mediated gene delivery has two types of cytotoxicity. immediate and delayed toxicities. ${ }^{16}$ PEI-mediated gene delivery protocols use net cationic complexes with an excess of PEI to maintain equilibrium between the complexed and dissociated forms in solution. ${ }^{17}$ However. it is not clear which of the complexed and dissociated forms of $\mathrm{PEI}$ is involved in the delayed toxicity.

In this study, the cytotoxicity was investigated with free PEI or PEI/DNA complex. The cell viability was measured by MTT assay and the level of apoptosis was evaluated by TUNEL assay. The results suggest that PEI/DNA complex contributes to the delayed toxicity by inducing apoptosis.

\section{Materials and Methods}

Preparation of pCMV-Luc. pCMV-Luc was introduced into $E$. coli strain DH5a, and purified by Qiagen Plasmids Maxi Kits (Qiagen, Valencia. CA). Purity of pCMV-Luc was certified by $\mathrm{OD}_{26 \mathrm{i}} / \mathrm{OD}_{\text {si }}$ ratio. The concentration of plasmid DNA was determined using $1\left(\mathrm{OD}_{\hat{6} \mathrm{ij}}\right)=50 \mu \mathrm{g}$ of DNA. Plasmid DNA was stored at $-20^{\circ} \mathrm{C}$. until use.

Cell culture and transfection. Human embryonic kidney 293 cells were grown in DMEM with $10 \%$ FBS. The cells were routinely maintained at $37^{\circ} \mathrm{C}$ in an incubator with a humidified atmosphere containing $5 \% \mathrm{CO}_{2} / 95 \%$ air. For the transfection studies. the cells were seeded at a density of 2.5 $\times 10^{5}$ cells/well in 6-well flat-bottomed microassay plates (Falcon Co.. Becton Dickenson. Franklin Lakes. NJ) 24 hrs before transfection. PEI/pCMV-Luc complexes were prepared at a $5 / 1 \mathrm{~N} / \mathrm{P}$ ratio. ${ }^{18}$ Before transfection. the medium was 
replaced with $2 \mathrm{~mL}$ of fresh DMEM without FBS. Then. free PEI or PEI/pCMV-Luc complexes were added to the cells. The amount of PEI per well was fixed. As controls. naked DNA was added to the cells. The cells were then incubated for 4 hrs at $37^{\circ} \mathrm{C}$ in a $5 \% \mathrm{CO}$. incubator. After 4 lurs the transfection mixtures were removed and $2 \mathrm{~mL}$ of fresh DMEM medium containing FBS. The cells were incubated for indicated time at $37^{\circ} \mathrm{C}$.

MTT assay. Evaluation of cytotoxicity was performed by the 3-(4.5-dimethylthiazol)-2.5-diphenyltetrazolium bromide (MTT) assay. The cells were seeded at a density of $2 \times 10^{4}$ cells/well in 96-well microassay plates (Falcon Co., Becton dickenson. Franklin Lakes. NJ), and incubated for 24 hrs before transfection. The medium was replaced with fresh DMEM medium without FBS before transfection. Free PEI or PEL/pCMV-Luc complexes were added to the cells. The amount of PEI per well was fixed. After the incubation at 37 ${ }^{\circ} \mathrm{C}$ for 4 hrs. the transfection mixture was replaced with 100 $\mu \mathrm{L}$ of fresh DMEM medium supplemented with $10 \%$ FBS. The cells were incubated for indicated time at $37^{\circ} \mathrm{C}$. After the incubation. $24 \mu \mathrm{L}$ of $2 \mathrm{mg} / \mathrm{mL}$ MTT solution in PBS was added. The cells were incubated for an additional $4 \mathrm{hrs}$ at 37 ${ }^{\circ} \mathrm{C}$ and then MTT-containing medium was aspirated off and $150 \mu \mathrm{L}$ of DMSO was added to dissolve the formazan crystal formed by live cells. Absorbance was measured at $570 \mathrm{~mm}$. The cell siability (\%) was calculated according to the following equation:

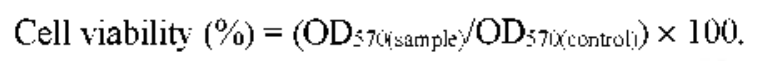

where the $\mathrm{OD}_{\text {s7l(sample) }}$ represents the measurement from the wells treated with pCMV-Luc. free PEI. or PEL/pCMV-Luc complex and the $\mathrm{OD}$ 57(icontoli) represents the measurements from the wells treated with PBS buffer only.

Luciferase assay. After transfection. the cells were washed with PBS twice and $200 \mu \mathrm{L}$ of reporter lysis buffer (Promega. Madison. WI) was added to each well. After 15 min of incubation at room temperature the cells were harvested and transferred to microcentrifuge tubes. After 15 sec of vortexing the cells were centrifuged at $11 \mathrm{k} \mathrm{rpm}$ for 3 $\mathrm{min}$. The protein concentrations of the extracts were determined by using Pro-measure protein assay kit (Intron Bioteclunology: Seoul. Korea). Luciferase activity was measured in terms of relative light units (RLU) using a Luminometer (TD-20/20. Turner Designs. Sunnyvale. CA). The funal values of luciferase were reported in terms of $\mathrm{RLU} / \mathrm{m}$ g total protein.

Colorimetric TdT-mediated dUTP nick end labeling (TUNEL) assay. DeadEnd ${ }^{\mathrm{TM}}$ colorimetric apoptosis detection system (Promega. Madison. WI) was used to detect apoptotic cell death in situ in the transfected cells. Briefly. the cells were attached to Poly-Prep ${ }^{\text {TM }}$ slides (Sigma, St. Louls. MO) and treated with naked pCMV-Luc, free PEI. or PEI/pCMV-Luc complex. The cells were fixed by immersing the slides in $10 \%$ buffered formalin and permeabilized by immersing the slides in $0.2 \%$ triton X-100 solution. After the cells were washed in PBS. the cells were incubated in equilibration buffer ( $200 \mathrm{mM}$ potassium cacody late $\mathrm{pH} 6.6$.

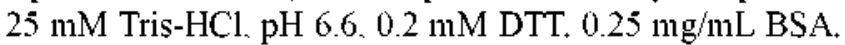
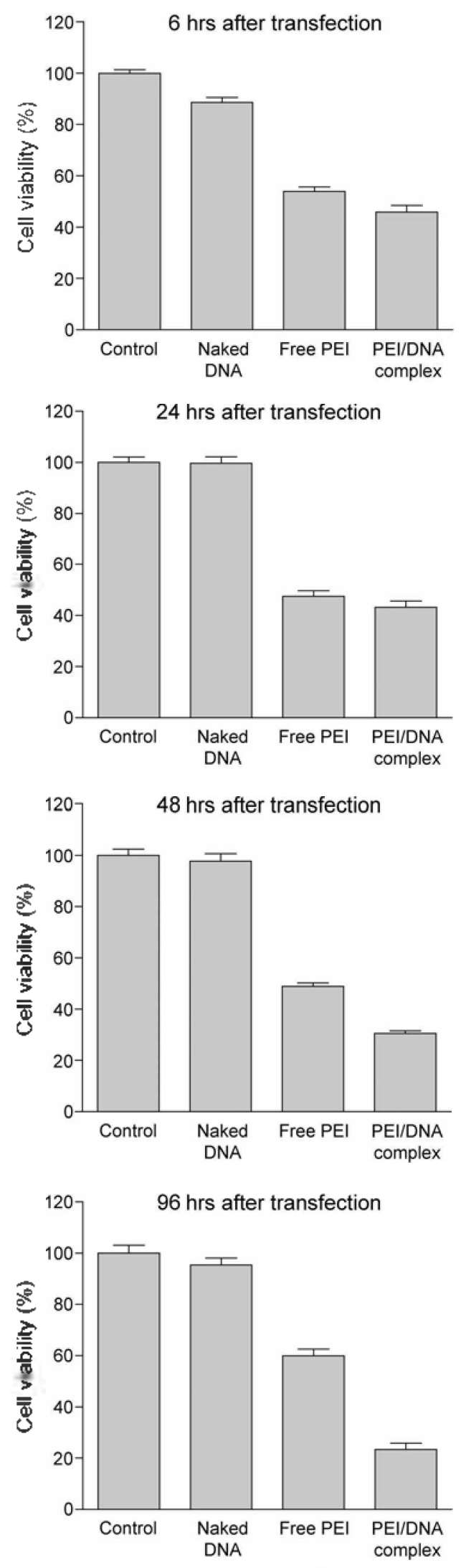

Figure 1. Cytotoxicity of naked DNA, free PEI, or PEI/DNA complex. Náked pCMV-Luc, free PEI, and PEI/pCMV-Luc complexes were transtected to 293 cells. After transfection, cell viability was measured by MI' assay. 'The data is expressed as mean values ( \pm standard deviation) of six experiments. 
and $2.5 \mathrm{mM}$ cobalt chloride) containing biotiny lated nucleotide mix and TdT (temminal deoxynucleotidyl transferase. 25 units) enzyme at $37^{\circ} \mathrm{C}$ for $1 \mathrm{hr}$. The reaction was stopped by immersing the slides in $2 \times \mathrm{SSC}(0.3 \mathrm{M} \mathrm{NaCl}$ and $30 \mathrm{mM}$ sodium citrate $\mathrm{pH} \mathrm{7.0)}$. The cells were incubated in $0.3 \%$ hyddrogen peroxide and then with streptavidin HRP (horseradish-peroxidase) diluted in $1 \times$ PBS. The cells were incubated with $\mathrm{DAB}$ (diaminobenzidine) components. rinsed several times in deionized water, and mounted in an aqueous or permanent mounting medium. Each slide was observed under a light microscope

\section{Results and Discussion}

To evaluate the toxicities of free PEI and PEI/DNA complex. MTT assay was performed after the treatment of naked DNA free PEI or PEUDNA complex. At 6 hrs after transfection. free PEI and PEVDNA complex showed significant toxicity to cells with $58 \%$ and $52 \%$ viability. respectively (Fig. 1). The viability of the cells incubated with free PEI was around $50-60 \%$ compared to control. showing similar toxicities at all time points. However. the viability of the cells incubated with PEV/DNA complex was continuously decreased. At 6 hrs the viability of the cells was $52 \%$ and was decreased to $23 \%$ at 96 hrs. Since the transfection mixture was removed after 4 hrs of incubation. the delayed toxicity of the PEI/pCMV-Luc complexes may be due to the PEV/pCMV-Luc complexes that were intemalized or simply bound to the cell surface. The results showed that PEI/DNA complex had immediate and delayed toxicities. while the toxicity of free PEI did not.

The luciferase gene expression profile was evaluated by

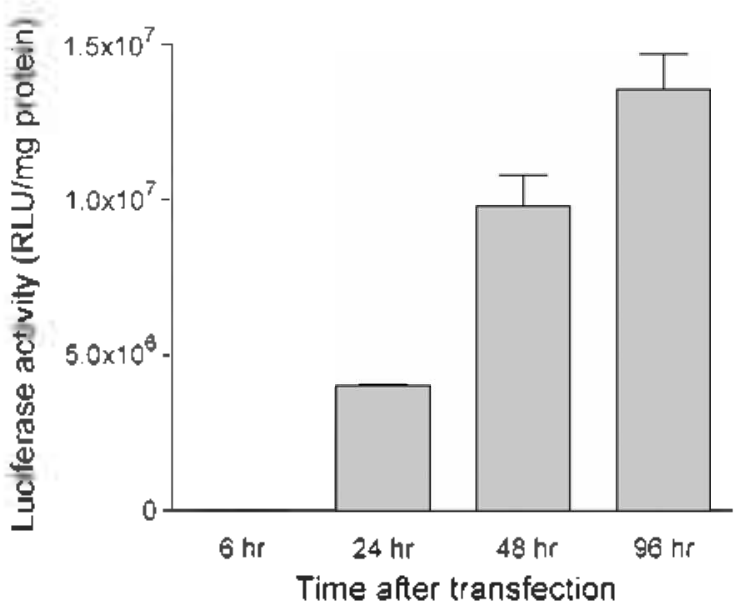

Figure 2. (iene expression depending on time atter the transfection of PEI/DNA complex. PEI/pCMV-Luc complex was prepared as described in Materials and methods and transtected to 293 cells. Transtection efficiency was measured by luciferase assay at each time point. The data is expressed as mean values ( \pm standard deviation jo four experiments.

luciferase assay. The transfection was performed with naked pCMV-Luc. free PEI, or PEVDNA complex. The controls with naked pCMV-Luc and free PEI did not show any detectable gene expression (Data not shown). In the case of PEVDNA complexes. the gene expression level is negligible at $6 \mathrm{hrs}$ after transfection (Fig. 2). The gene expression level increased gradually along with time (Fig. 2). Since the transfection mixture was removed after 4 hrs of incubation. entry of PEL/pCMV-Luc complexes into cells did not increase significantly after the incubation. For gene expression. DNA should be released for the complex. PEI has high charge

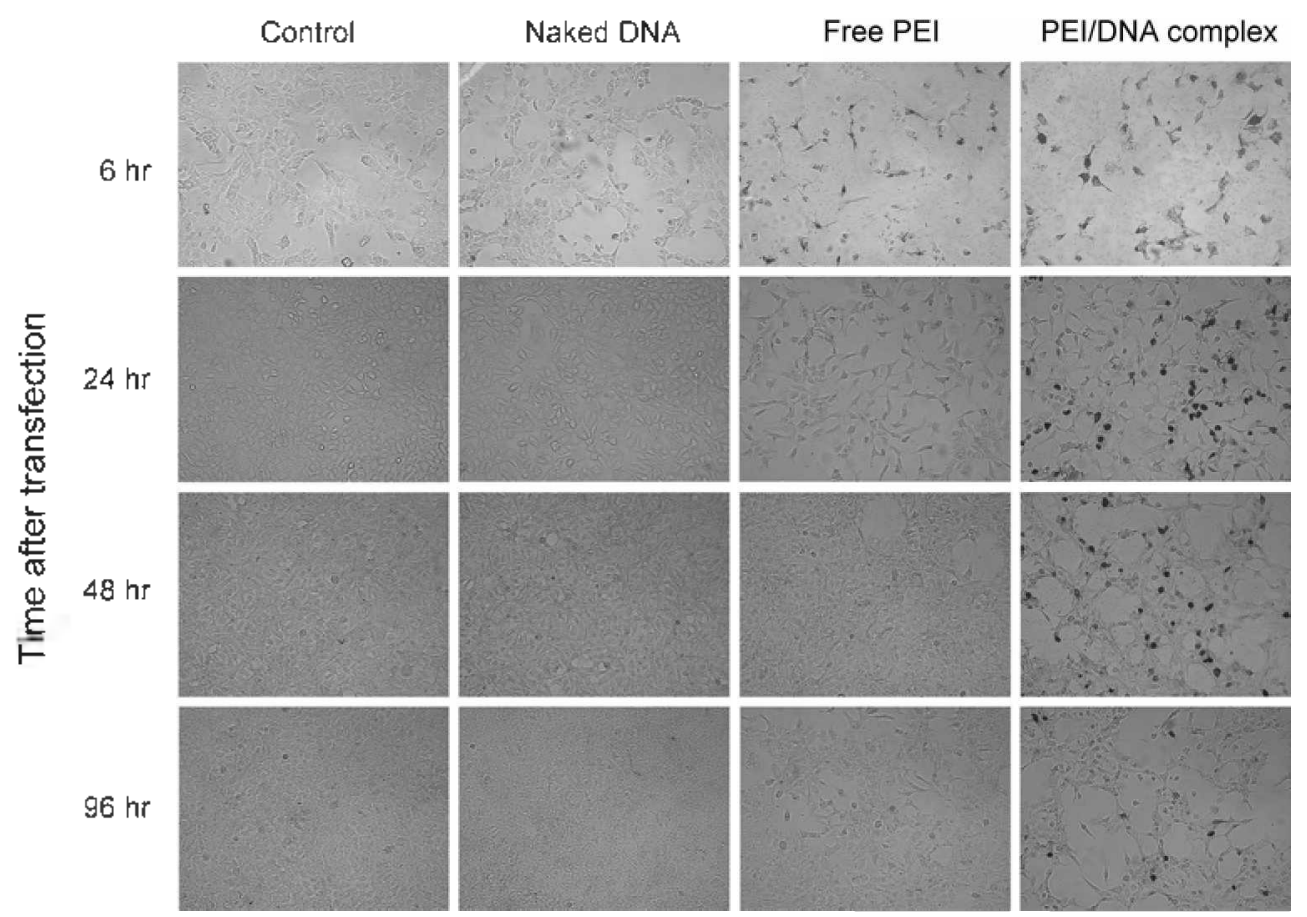

Figure 3. TUNEL assay after transfection of naked DNA, free PEI, or PEI/DNA complex. Naked pCMV-L uc, free PEI, and PEI/pCMV-Luc complexes were transfected to 293 cells. After transfection, the level of apoptosis was measured by TUNEL assay at each time point. 
density and release of DNA in the cytoplasn or nucleus may be a slow process. The increase of gene expression may be due to slow release of DNA from PEL/pCMV-Luc complexes.

The level of apoptosis was measured after transfection by TUNEL assays (Fig. 3). The control cells and naked DNA transfected cells did not show any apoptosis at all time points. However, free PEI and PEVDNA complex samples showed significant level of apoptosis at 6 hrs after transfection. However apoptotic cells were not observed in the free PEI treated cells after 24 hrs after transfection (Fig. 3). The PEVDNA complex transfected cells showed significant level of apoptosis up to 96 hrs after transfection (Fig. 3). This results indicate that apoptosis in the PEL/DNA complex transfected cells at 24.48 and 96 hrs is not due to free PEI. but PEI/DNA complex.

It was previously suggested that PEI-mediated gene delivery might have two stages of toxicity: ${ }^{16}$ Ln the PEI-nediated gene transfection. free PEI and PEI/DNA complexes are at equilibrium in the complex solution. Due to the high charge density of free PEI. PEI aggregates at the surface of plasma membrane and rupture the cell. which induces immediate toxicity. ${ }^{15}$ However, delayed toxicity may be associated with cellular process. For transgene expression. DNA should be released from the complex after internalization of $\mathrm{PEI} / \mathrm{DNA}$ complex. The release of DNA from the polymer/DNA complex after entry into cells is one of the requirements for efficient gene delivery. Decomplexation produces free DNA for the access of transcriptional machinery. which may increase gene expression. However. release of DNA also produces free PEI in the cell. After release of DNA the dissociated PEI may interact with various cellular components with negative charges. This interaction may interfere their normal cellular functions and induce apoptosis. Therefore the cytotoxicity of PEI/DNA complex may be closely related to the level of gene expression in the PEI-mediated gene delivery. Indeed. the cytotoxicity of the transfection became higher with increasing level of gene expression.

In summary, in the PEI-mediated gene transfection. PEV/
DNA complex induced immediate and delayed toxicities. while that of free PEI did not induce delayed toxicity. In addition. PEI/DNA complex induced apoptosis of the cells. The delayed cytotoxicity of PEI/DNA complex may be closely related to decomplexation of the complex in the cells.

Acknowledgments. This work was supported by the research fund of Hanyang University (HY-2005-N) and Seoul R \& BD program (10538).

\section{References}

1. Wilson. J. M. N. Engl J. Hed 1996. 33t. 1185.

2. Han1. S.: Mahato. R. I.: Sung. Y. K.: Kim. S. W. Mol. Ther: 2000. 2. 302

3. Lee. M.: Kim. S. W. Pham News 2002. 9. 407.

4. Kabanov, A. V: Kabanov, V. A. Bioconjug. Chem 1995, 6.7

5. Lee. M.; Kim, S. W. Pham Res. $2005,22,1$.

6. Choi. J. S.: Choi, M. J.: Ko. K. S.: Rhee, B. D.; Pak. Y. K: Bang. I. S.: Lee. M. Bull. Kot Chem. Soc. 2006. 27. 1335.

7. Kang. H. C.: Lee. M.: Bae. Y. H. Crit. Rev: Eukuryot. Gene Expn: 2005. 15.317.

8. Boussif. O.: Lezoualch, F.: Zanta. M. A: Mergny. M. D.; Scherman, D; Demeneix, B; Behr, J. P. Proc. Natl Acad Sci. USA $1995,92.7297$

9. Boussif. O.: Zanta. M. A.: Behr. T. P. Gene Ther 1996. 3. 1074

10. Bent1s. I. M.: Maheshwari. A.: Furgesont. D. Y.: Mahato. R. I.: Kiml. S. W. J. Dnng Torget 2001. 9. 123.

11. Sagara. K.: Kim, S. W. J. Control. Release 2002, 79, 271

12. Suh. W.: Han. S. O.: Yu. L.; Kim, S. W. Hol. Ther 2002, 6, 664

13. Ogris. M; Brunner. S; Schuller. S; Kircheis, R.: Wagner. E. Gene Then 1999.6.595.

14. Lim. Y. B.: Han. S. O.: Kong. H. U.: Lee. Y.: Park. J. S.: Teong. B.: Kinn. S. W. Phorm. Res. 2000. 17.811

15. Fischer. D.: Bieber, T.: Li, Y.: Elsasser, H. P.: Kissel. T. Pham. Res. $1999,16,1273$.

16. Godbey. W. T.: Wu, K. K.; Mitios, A. G. Bionaterials 2001. 22. 471

17. Kim. Y. H.: Park. J. H.: Lee M.: Kim. Y. H.: Park. T. G.: Kim. S. W. J. Control. Release 2005. 103. 209.

18. Lee. M.; Rentz, J.; Han. S. O.: Bull, D. A,; Kim. S. W. Gene Ther: 2003. 10,585 